\title{
GARCILASO Y EL MODELO DE LA NUEVA CULTURA
}

Los Comentarios reales del Inca Garcilaso de la Vega pueden hoy ser leídos como un verdadero "texto de cultura"'. En primer lugar, porque organizan un modelo del sentido histórico, que hace del discurso del pasado un proyecto del porvenir. Y, en segundo lugar, porque implican un programa cultural de redefiniciones, cuya articulación es política. Por lo primero, el Inca Garcilaso convierte a la narrativa arcádica en una hipérbole histórica, característica de la historiografía humanista; es decir, reconstruye el Imperio incaico no sólo como otra Roma sino como la república neoplatónica que el humanismo renacentista confía a la virtud política. De ese modo, representa el relato arcádico como una utopía filosófica; y se complace en la melancólica paradoja de las inadecuaciones del discurso y la historia: el ideal de la república utópica humanista ha sido ya realizado por los incas, y ha sido destruido por los conquistadores. No obstante, por lo segundo, por ser un programa cultural de definición política, los Comentarios no se limitan a la hipérbole histórica sino que se configuran como otro de los ejemplos de la actualidad y la virtualidad de lo nuevo. Así, son un fruto de la abundancia de Indias, tanto como los otros frutos fecundos que demuestran que las Indias son la realización superior de España y del humanismo; pero estos Comentarios se definen no sólo por su equivalencia natural y moral sino por el sentido político de su poderoso reclamo a nombre de lo diferente.

Por lo mismo, ya desde su carácter narrativo doble (arcadia y utopía, historia y filosofía política, reconstrucción filológica y

${ }^{1}$ Puede consultarse B. A. Uspensky et al., "The Semiotic Study of Culture', en Jan van der En \& Mojmir Grygar (eds.), Structure of Texts and Semiotic of Culture, Mouton, The Hague, 1973; y también J. M. Lotman, "Problems in the Typology of Culture", en Daniel P. Lucid (ed.), Soviet Semiotics, Johns Hopkins University Press, Baltimore, 1977. 
construcción figurativa) los Comentarios reales dan forma a los dos grandes modelos discursivos del relato sobre América: el discurso de la abundancia y el discurso de la carencia. El discurso de la abundancia suma imágenes de la Edad de Oro, adapta las virtudes del Príncipe cristiano al patriarcado incaico, incluye en Europa los bienes de Indias y en éstas a Europa como una semilla providencial. Pero, sobre todo, la abundancia nos enseña, a través de sus ejemplos de verosimilitud puesta a prueba, que la realidad haciéndose se convierte en el modelo natural de la filosofía moral y de la cultura naciente. Ni la naturaleza ni la historia están acabadas de hacer, y sus cambios y transformaciones se abren fecundamente desde el presente de las incorporaciones como un modelo del porvenir. En cambio, el discurso de la carencia (un verdadero contradiscurso) se trama en tanto lamento y denuncia, con poderosa capacidad demostrativa de la violencia histórica, la destrucción irracional y la desigual calidad de las empresas humanas. La carencia se abre como un contrasentido histórico pero también como el extravío del presente; como su amenaza en la mala administración, el faccionahsmo, el desvalor de lo conquistado y la privación de los derechos naturales. En su lectura de los hechos, el Inca Garcilaso accede a todos los protocolos de su tiempo, pero no deja de tramar, muchas veces con sutileza simétrica, la melancólica ironía de la pérdida en la misma demostración de la abundancia. Sabemos que el libro se escribe para disputar la distorsión política promovida por los historiadores y comentaristas toledanos; pero se escribe también como una filosófica reflexión crítica, en tiempos imperiales de apogeo, demostrando, en su laberíntico modo contrastivo e inductivo, que los poderes de acopio conllevan destrucción y olvido.

Contra ese olvido el Inca Garcilaso reconstruye la memoria como el espejo de la identidad abundante en la carencia que borra y distorsiona. Así, el libro construye un archivo identificatorio de los sujetos que, en el cambio histórico desencadenado, ver sus destinos sociales en zozobra. Si la noción de continuidad den. tro del cambio es central a la conciencia histórica humanista, er el Inca Garcilaso se trata, además, de una vasta labor de repara. ciones: no hay un modelo de inter-relaciones dado, sino que lá discontinuidad histórica, con su violencia y su pérdida, tal come se recuenta en la segunda parte de los Comentarios, disuelve los he. chos y vacía el sentido. Por eso, el Inca procede a reorganizar lo: hechos en la perspectiva de la narración política, allí donde lo: ejemplos son una demostración filosófico-moral y la historia ur 
modelo cultural. Escribir la historia, lo sabemos, es hacerla. Y para el Inca Garcilaso este rehacer histórico se plantea como una larga disputa por la información y su sentido. Por lo tanto, deberá elaborar una compleja estrategia discursiva que se le aparece como un "gran laberinto". Se trata del laberinto historiográfico, es decir, de la grafía del hecho y del hecho de la escritura².

En lo que sigue me gustaría poder demostrar la siguiente hipótesis: el Inca Garcilaso de la Vega no escribe como un español aculturado pero tampoco como un mestizo cultural. Escribe, en verdad, como un "indio" (tal como se llama a sí mismo en su traducción de León Hebreo), como un "inca" (tal como se nombra a sí mismo como si renombrara a su padre), como un testigo indígena de la historia que lo destina a la escritura. La crítica, al discutir las fuentes historiográficas del Inca, no ha podido sino verificar su rica formación literaria, pero de ello no es preciso concluir que se trata de un producto homogéneo de sus lecturas ni, mucho menos, que incorpora el Incar'o al archivo occidental. Aun si se trata, evidentemente, de un heredero de la filología, no se es un gramático literal sino uno cultural y, por lo mismo, su método es político. Otros críticos han preferido ver en la obra del Inca una metáfora biológica de su mestizaje, y han difundido la noción, no menos metafórica, de una conciliación amestizada, indígena y española, que haría de su obra una homogeneización de ambos mundos en la síntesis supuesta de la historia colonial y el destino católico. Evidentemente, ambas tendencias documentan bien su interpretación. Pero, creo yo, limitan con su propia información al seguir una mecánica deduccionista y reductiva. Y,

${ }^{2}$ Sobre este punto son esclarecedoras las observaciones de Michel DE CERTEAU en "La operación historiográfica", en su libro La escritura de la historia, Universidad Iberoamericana, México, 1985. Puede verse también Derek AтTRIDGE et al. (eds.), Post-structuralism and the Question of History, Cambridge University Press, Cambridge, 1987. EnR IQUe PUPO-WALKER ha discutido la construcción narrativa de los Comentarios en su Historia, creación y profecia en los textos del Inca Garcilaso, J. Porrúa Turanzas, Madrid, 1982, y el desarrollo de la prosa de ficción en La vocación literaria del pensamiento histórico en América, Gredos, Madrid, 1982. Sobre la dimensión histórica de los Comentarios son importantes los ensayos de José Durand reunidos en su libro El Inca Garcilaso: clásico de América, Sepsetentas, México, 1976. Fuentes historiográficas del Inca son analizadas también por Aurelio Miró Quesada en El Inca Garcilaso y otros estudios garcilasistas, Cultura Hispánica, Madrid, 1971. Una alerta discusión sobre la lectura de las crónicas es la de Carlos Araníbar, "Algunos problemas heurísticos en las Crónicas de los siglos XVI-XVII", Nueva Coronica, Lima, 1963, núm. 1, 102-135. 
sobre todo, no responden por un modelo cultural implícito en la obra sino por modelos externos a ella. El primero, internalizado por su occidentalismo difusionista (que equivale a un eurocentrismo fatal); el segundo, el del mestizaje, naturalizado por su suma neutralizadora de las partes (que equivale a la ideología dominante del estado nacional). Para no disolver al Inca en la enciclopedia de su tiempo y para evitar convertirlo en la metáfora de una nacionalidad, que nunca es homogénea en nuestros países multinacionales, nos proponemos releer los Comentarios reales como parte de otro proceso: el de las apropiaciones, que la cultura colonial dominada produce, a través de las cuales las culturas nativas, indígenas y multinacionales, evolucionan incorporando nueva información, reparando sus circuitos, afirmando sus sistemas y, en fin, procesando la violencia y proyectando el porvenir. Así, en tanto texto de cultura, los Comentarios serían otro de los actos de reapropiación que la nueva cultura ejerce en el archivo de la cultura hegemónica ${ }^{3}$.

Desde esta perspectiva, es parte de la estrategia discursiva del Inca Garcilaso la necesidad de re-escribir la historia nativa utilizando el repertorio de la historia europea. Este acto historiográfi-

${ }^{3}$ En los últimos años, desde la etnohistoria tanto como desde la crónica del discurso cultural, se viene realizando un esfuerzo consistente por precisar las versiones indígenas y las representaciones nativas que hacen suya la alfabetización, los repertorios discursivos, los códigos culturales españoles, adaptados y trans-codificados por la formación de una lectura aborigen, heteróclita y descentradora. N. WACHTEL, en La vision des vaincus, Gallimard, Paris, 1971, todavía asume la noción de "aculturación", pero no sin advertir que no se puede entenderla como parte de la empresa colonial sino que "al contrario, la aculturación revela la crisis, se confunde con ella"' (p. 212). Y aunque considera a Garcilaso dominado por la necesidad humanista de unidad, afirma que los Comentarios "son una obra de combate" porque la interpretación de Garcilaso se opone a la historiografía toledana y que la obra es "un rechazo del Perú colonial" (p. 245). En lugar de la noción neutralizadora y niveladora de aculturación preferimos la de transcodificación, que implica un desplazamiento de las adaptaciones informativas al sistema de la propia cultura. No es casual que José María Arguedas se definiera en esta otra dirección nativa cuando afirmó "Yo no soy un aculturado" (1968). Los trabajos de RolenA Adorno sobre Guaman Poma de Ayala sistematizan el análisis de la textualidad cultural aborigen, sobre todo su Guaman Poma, Writing and Resistance in Colonial Peru, University of Texas Press, Austin, 1986, y la colección de ensayos Cronista y príncipe, la obra de don Felipe Guaman Poma de Ayala, Universidad Católica, Lima, 1989. Véase también Raguel Chang-Rodríguez, Violencia y subversión en la prosa colonial hispanoamericana, J. Porrúa Turanzas, Madrid, 1982, y BeATRIz PaStor, Discursos narrativos de la conquista: mitificación y emergencia, Norte, Hanover, 1988. 
co, por el cual Europa escribe las Indias, no se cumple como mera occidentalización del Incario, y mucho menos como una mecánica aculturación. En efecto, la historia del Incario no es un capítulo más de la historia occidental sino una verdadera puesta en crisis del orden de su archivo: la historia, su gramática, su filosofía moral, su didáctica, su ideal político, dan cuenta no de las virtudes del sensus historicus europeo sino de la autorrevelación cultural del Perú a través de y gracias a la hipérbole retórica humanista. El Incario es traducido por el Inca a la lengua filosófica de su tiempo en una estrategia de lectura y escritura que hace de la traducción cultural una reconstrucción del sujeto americano en el nuevo discurso histórico. Este nuevo discurso está hecho de resúmenes, alusiones, re-codificaciones y nuevos ordenamientos; esto es, de una textura formal que abre el umbral (un espacio marginal, un margen de escritura) donde el sujeto americano pueda enunciar su nombre entre los lenguajes, su renombre entre los repertorios de los saberes legítimos. Utilizar de este modo el archivo para reordenarlo de acuerdo con los objetos de la diferencia cultural, supone incorporar la idea del archivo a la alteridad efectiva de las cosas y los nombres de Indias. Si el Incario no conoció la escritura, se apodera, en este libro, de las escrituras de la tradición para inscribir su narrativa entre los relatos del origen y del fin, como un relato heroico del recomienzo del acto de narrar desde fuera pero internamente.

Un ejemplo revelador de esta estrategia discursiva lo encontramos en la peculiar reconversión que de la filología hace el Inca Garcilaso. Si, en efecto, "la estructura del lenguaje se relaciona con la estructura del conocimiento y así con la definición de la realidad histórica" 4 , las relaciones de retórica, historia y filosofía en los Comentarios reales requieren todavía ser articuladas a partir del modelo lingüístico que reorienta su escritura. La "nostalgia crítica" que Petrarca exhibe en tanto filólogo de la Antigüedad clásica perdida que busca recuperar palabra a palabra, parece

${ }^{4}$ Nancy S. Struever, The Language of History in the Renaissance, Princeton University Press, Princeton, 1970. También dice lo siguiente: "The theory and structure of spoken and written discourse reflect the changing tensions between rhetorical exigencies and philosophical or theological axioms; at every crucial change in the temper of the Western intellectual tradition a new resolution of these conflicting demands alters the configurations of linguistics, literature, and pedagogy" (p. 6). Tratándose de una reestructuración del discurso desde una experiencia colonial, la empresa del Inca reordena estas configuraciones para replantear la teoría cultural dominante. 
resonar en la diligencia filológica del Inca Garcilaso, cuya lengua materna, el quechua, se le impone como el modelo cultural de la traducción, y no sólo la literal, que debe suscitar para que en la recomposición crítica de la lengua madre se sostenga tanto la realidad perdida como la memoria personal, tanto la especificidad de lo otro como la verdad de lo diferente, tanto la bondad de lo antiguo como la fecundidad de lo nuevo. La fidelidad de la lengua nativa es el modelo de la verosimilitud de una narrativa que incorpore los términos antagónicos como dos sistemas paralelos y equivalentes, que no deben borrarse el uno al otro, que podrían nutrirse para producir (como el árbol barroco del injerto, que el Inca nos ofrece) nuevos y mayores frutos. Así, la filología es la más reciente de las disciplinas quechuas: la autorrevelación cultural del sujeto en su lenguaje ${ }^{5}$.

Petrarca nos dice que la copia de los Institutos de oratoria de Quintiliano llegó a sus manos "despedazada y mutilada", y el sentido dramático de pérdida que comunica no es diferente al que expresa el Inca Garcilaso cuando nos dice, una y otra vez, que el manuscrito del padre Blas Valera llegó a las suyas como "papeles rotos" después del saqueo inglés del puerto de Cádiz. Si Petrarca lamenta la mano del tiempo inexorable, Garcilaso conoce bien la mano de la historia, irreverente y no menos destructora. La pasión y devoción filológica se expresa en el maestro y en el discípulo con el mismo emblema de la lectura que restaura el palimpsesto de la lengua, como un saber más cierto, a través de esos papeles rescatados donde la escritura triunfa sobre los poderes arbitrarios. Garcilaso cita, glosa, resume, comenta y amplía el manuscrito del padre Blas Valera, como una fuente de autoridad superior, más fiel incluso que las fuentes históricas a la mano porque su certidumbre se basa en un privilegio de la lengua: el padre Valera es, como Garcilaso, un mestizo, un quechua hablante, un sabio nativo, cuyo texto (supuestamente escrito en latín) no alcanza a cumplir su destino comunicativo, su realización histórica, sino a través de su incorporación al texto del Inca. Así, estos "papeles rotos" son un discurso interno a la obra, y el padre Valera una suerte de interlocutor doble que sostiene a la escritura

${ }^{5}$ Donald E. Kelley trata la "nostalgia crítica" de Petrarca en su trabajo "Humanism and History", en Albert Rabil Jr. (ed.), Reinassance Humanism, Foundations, Forms and the Disciplines, University of Pennsylvania Press, Philadelphia, 1988, t. 3, pp. 236-270. La dimensión filológica del Inca es tratada por Margarita Zamora en Language, Authority, and Indigenous History in the Comentarios Reales de los Incas, Cambridge University Press, Cambridge, 1988. 
no sólo con su autoridad clásica y erudita sino, sobre todo, con su apertura hacia la oralidad originaria, hacia el quechua. Es, por lo tanto, un traductor interno en la obra, que confirma y amplía la actividad mediadora del traductor Garcilaso. Reveladoramente, Garcilaso no traduce meramente del quechua hacia el español universal, sino de éste a aquél, en un cotejo de mutuo discernimiento comparatista y filológico; es decir, confirma el sistema de apropiaciones al incorporar a su diccionario quechua el otro, alterno, español. El plurilingüismo dialógico, por lo tanto, se instaura en el centro de la obra, como una de sus articulaciones culturales de persuasión política. Al citar los "papeles rotos" (figurativamente no son un libro, emblemáticamente aluden a una historia americana escrita por americanos, pero no sabemos, literalmente, cuán rotos), no es improbable que el Inca los reescriba, como ya hiciera el padre Las Casas en su memorable operación textual del diario de navegación de Cristóbal Colón. Haría falta un cotejo minucioso de las formas de cita que efectúa el Inca, pero también del estilo más circunspecto del padre Valera y del más narrativo de Garcilaso, si bien en el lenguaje de aquél son patentes algunos giros retóricos de éste. En cualquier caso, el Inca incorpora el texto de Valera a su propia estrategia diseursiva, al punto de hablar a través suyo, y viceversa, en una operación de traducción (quechua, latín, español) que, desde las primeras páginas, define la identidad de la obra a partir del modelo nativo del quechua. Así, la escritura adquiere la actualidad de la voz y la presencia articulada del pasado ${ }^{6}$.

Si Petrarca creyó que el latín ciceroniano proveía la mejor expresión de la realidad, el Inca Garcilaso evidentemente cree que el quechua es la matriz de la realidad, su centro generador. Una y otra vez vuelve al quechua, no solamente para asumir su condición de quechua hablante autorizado para revisar los errores de interpretación, que siendo pérdidas del lenguaje son extravíos de la realidad peruana; sino, esencialmente, para constatar la diferencia de lo real en la diferenciación de la lengua. De una a otra lengua, la realidad se hace transitiva, traducible pero no indistinta, porque en cada una el objeto y el sujeto responden por un código distinto, cuya racionalidad es cultural. Así, la mtegridad de la lengua es el derecho natural de la existencia de un pueblo, y esta convicción es una práctica y una visión política. Mientras que

${ }^{6}$ Sobre el padre Valera véase José Durand, "Los últimos días de Blas Valera", en Libro de Homenaje a Aurelio Miró Quesada, vol. 1., Lima, 1967. 
el latín sostiene tanto la autoridad historiográfica de lo escrito como la nobleza de la tradición, que abre su archivo al quechua para que inscriba en él su propia diferencia; el castellano, por su lado, se convierte en la lengua de la transacción, en el espacio de lo cotidiano, que el quechua remonta en su camino hacia el latín. En esas tres dimensiones, el Inca (que ha traducido los Diálogos de amor de León Hebreo, y cuyo latín, confiesa, es limitado) trama su estrategia de traslados, incorporaciones y legitimaciones. La cultura (información procesada, intercambiada, preservada) se le revela como una compleja producción de signos que tienen sentido en el espacio mayor de una comunicación plurilingüe y multiétnica; allí donde el sujeto es un héroe del discurso, un fundador del lenguaje que lo constituye, y en el que elabora su espacio virtual ${ }^{7}$.

"Soy el copista de aquellos cuya verosimilitud o mayor autoridad demanda que se les dé crédito" (Prefacio a De viris illustribus), escribió Petrarca; y Garcilaso, apoderándose de esa tradición autorial diversificada, convoca en sus Comentarios, junto al mestizo Blas Valera, el relato más hegemónico pero no menos humanista de Cieza de León y la reflexión más erudita y ortodoxa del padre José de Acosta. La robusta autoridad de Gómara y el alerta testimonio del contador Zárate completan su esquema de autoridades, verdaderas mediaciones de la información, que le permiten introducir en su narrativa un sistema de verificación crítico y puntual. Pero este acopio de pruebas no se limita a sostener la verdad de los hechos, ya que Garcilaso está interesado sobre todo en los efectos de la verdad, en la persuación de lo verosímil, en el orden que éste sostiene y en el lugar que ocupa histórica y culturalmente ${ }^{8}$. O sea, la narrativa se desdobla en discurso político. Por eso, en el mapa de las conexiones posibles con la tradición historiográfica no se puede dejar de considerar la noción histórica de Maquiavelo, que es fundamentalmente política. Para él, ya no se trata sólo de elogiar a Roma sino de criticarla y aprender

${ }^{7}$ Sobre la función cultural y etnológica de la traducción pueden consultarse SuSANa JÁKFALVI-LeIVA, Traducción, escriturary violencia colonizadora: Un estudio de la obra del Inca Garcilaso, Maxwell School, Syracuse University Press, Syracuse, 1984 y Regina Harrison, Signs, Songs, and Memory in the Andes, Translating Quechua Languague and Culture, University of Texas Press, Austin, 1989.

PUPO-WALKER, La vocación literaria del pensamiento histórico en América, pp. 74-76 anota la importancia de la verosimilitud en la historia, término que es ya utilizado por Petrarca. 
de su historia. Después de todo, el estudio del pasado puede servirnos para el porvenir. Y su Historie fiorentine termina con la muerte de Lorenzo de Medici en 1492, precisamente al comienzo de la más destructiva serie de nuevas invasiones "bárbaras"9. No es una coincidencia que los Comentarios reales terminen con la matanza que hace el tirano Atahuallpa de la familia real cuzqueña, a la que pertenece el propio Garcilaso, como bisnieto de Túpac Yupanqui, el antepenúltimo emperador inca. En una suerte de apéndice, Garcilaso cuenta que ha recibido una carta de los descendientes imperiales, que viven en el Cuzco, quejándose de su postración y reclamando justicia real; con lo cual el relato actualiza el pasado, y en la historia de su familia sobreviviente inscribe la suya propia, diferidamente pero del lado de los vencidos. De un modo no menos elocuente concluye la segunda parte de los Comentarios, la Historia general del Perí, con la matanza de Túpac Amaru I ordenada por el virrey Toledo, cuya violencia política y distorsión histórica deben habérsele aparecido como una aberración tiránica, lo que le mueve a disputar, en el discurso, la suerte del sentido histórico. Esos dramáticos finales de ambos libros evocan el modelo narrativo cíclico; y si la tragedia se repite es porque la verdad del pasado no es una lección moralmente asumida. El Inca, muchas veces, parece movido por la necesidad de comunicar la urgencia ética de la experiencia histórica.

Pero si por un lado se escribe la historia del Incario para reescribir el presente con un modelo del porvenir (también aquí la oratio se decide como ratio), por otro lado se da cuenta de los procesos formativos de la nueva cultura, ya que la historia de los orígenes es literalmente un catálogo de las adaptaciones, transplantes e incorporaciones. Por ello, la información debe ser primero procesada, y en ello el Inca lleva la palabra reguladora de la lengua nativa. Se trata de un principio de catalogación. "Los españoles —nos dice en el capítulo 4 del libro segundo- aplican otros muchos dioses a los incas por no saber dividir los tiempos y las idolatrías de aquella primera edad y las de la segunda. Y también por no saber la propiedad del lenguaje para saber pedir y recibir la relación de los indios" 10 . Esta "falta de relación verdadera que tuvieron los historiadores" confunde las series y los géneros, tanto como la ignorancia de la pronunciación confunde los significa-

${ }^{9}$ Sigo a Donald R. Kelley, art. cit., en este resumen.

${ }^{10}$ Inca Garcilaso de la Vega, Comentarios reales de los Incas, 2 ts., ed. de Ángel Rosenblat, Emecé, Buenos Aires, 1943. 
dos. En uno de los ejemplos, el Inca narra la lección de lingüística quechua que da a un sacerdote, lección, nos dice, a viva voce, "que de otra manera no se puede enseñar". Ese sacerdote es un maestro de quechua, pero su deficiente competencia sugiere que el procesamiento de la otra cultura falla aquí seriamente. Esa lengua que "mamé en la leche", repite, le lleva a traducir y a corregir, a mediar entre las lenguas y los hablantes con la verdad de la suya propia.

En cambio, en la famosa historia de los melones (un capataz envía al dueño de la hacienda diez melones y una carta que transportan dos indios, a quienes les advierte que no coman de la fruta porque lo dirá la carta), nos encontramos con dos series de signos que los nativos no pueden procesar. La primera es, claro, la letra, pues ignoran la escritura; de modo que cuando deciden comerse un melón esconden la carta para que no los vea, pero cuando el dueño lee la misiva descubre la falta de los indios, quienes quedan abrumados por el poder de la letra. No es casual que la letra forme parte de las facultades de los amos, y que la ignorancia indígena sea parte de la "simplicidad de los indios del Nuevo Mundo" (cap. 29, libro nono). Pero la otra ignorancia es menos evidente. En el camino, llevando los melones, uno de los indios le dice al otro: “¿No sabríamos a qué sabe esta fruta de la tierra de nuestro amo?"' Se trata, dice el Inca, de los primeros melones que se dieron en Lima, en Pachacámac, que fue el centro religioso de la costa peruana. No conocer la escritura es, en este ejemplo, paralelo al desconocimiento del sabor del fruto de una tierra que "mostraba su fertilidad". Esa doble ignorancia supone la pérdida de la misma tierra, que ya no es de los indios sino de "nuestro amo". Y, sin embargo, el ejemplo de la pérdida es la ganancia del relato: no sólo por gracia de la historia popular, que asocia los orígenes a la fábula de la abundancia, sino porque esa historia popular es una alegoría del conocimiento socialmente sancionado. Los indios ignoran saber y sabor, pero el relato del Inca les devuelve, con la palabra del origen, la sabiduría de las reparaciones equivalentes y el gusto de la fábula.

En efecto, el proceso del intercambio sígnico (después del procesamiento de la información, el otro mecanismo definitorio de la cultura) se cumple en los Comentarios reales como una intensa. proliferante, fecunda interacción hecha sobre la "fertilidad" d la tierra. El discurso de la abundancia registra el repertorio de estos intercambios, que son emblemáticos de las incorporacione: que hacen las Indias de la nueva información llegada de España 
Si la naturaleza es procesal, el mundo natural se enriquece gracias a esta fecundidad del Nuevo Mundo. Y no sólo por la historia providencialista que hace de las Indias el destino de España, su realización; sino porque en el discurso crecen estos frutos y frutas como la nueva hipérbole americana de la representación barroca. $\mathrm{Si}$, en efecto, en la perspectiva, el naturalismo de la imagen supone una presencia del sujeto renacentista en el mundo, en la percepción de los nuevos objetos americanos (como el famoso rábano gigante) opera, en cambio, un nuevo sistema de representación: el objeto no obedece a la geometría de la perspectiva, al control nominal de la serie y al dictamen de los sentidos; el objeto excede el campo de la nominación y de la visión, y se hace inverosímil al punto de poner a prueba la verificación. El Inca se apresura a sumar testigos (un interlocutor autorizado le dice: "yo soy testigo de vista de la grandeza del rábano") pero no deja de asombrarse de su propio registro: "temía poner el grandor de las cosas nuevas de mieses y legumbres que se daban en mi tierra, porque eran increíbles para los que no habían salido de las suyas" (cap. 29). Estas cosas nuevas son emblemas del intercambio, pero de un intercambio sígnico no previsto en los sistemas de la representación, ya que la naturaleza en Indias transfigura el objeto con el nuevo valor de la abundancia. Hasta el padre Acosta reconoce la peculiaridad de estos transplantes, y se complace el Inca en ello ya que su "autoridad refuerza mi ánimo para que sin temor diga la gran fertilidad que aquella tierra mostró a los principios con los frutos de España, que salieron espantables y increíbles" (cap. 29).

Pero estos objetos que no corresponden ya al sistema de clasificación y descripción español proliferan no sólo en la tierra fértil sino en la fertilidad del discurso. Es en el discurso donde su carácter barroco actúa como el emblema de la nueva cultura. En primer lugar, porque la realidad europea es transformada por el nuevo sistema de las incorporaciones; y en segundo lugar, porque las Indias ponen en crisis los medios de la representación homogeneizadora, eurocentrista, y demandan su lugar propio y su nuevo discurso. Este barroco mmanentista y fecundo se define así en tanto sistema de representación alterno. Los signos tienen nombre pero adquieren en este nuevo discurso un re-nombre imprevisto. Por lo tanto, el repertorio de la Edad de Oro ocurre como una segunda fundación. Lo que el Inca llama "los principios" son un espacio edénico recobrado de la mitología de los orígenes pero renombrado en su nuevo recomienzo por el discurso de la 
cultura naciente. Así, el mundo natural se convierte en el modelo fecundo del modelo cultural ${ }^{11}$.

Por eso, el árbol nativo que da nuevos frutos con el injerto español se levanta como el emblema de estas incorporaciones y crecimientos. También por ello los mestizos se desarrollan desde la fuente aborigen, haciendo suya la información disponible. En el Prólogo a la segunda parte de los Comentarios leemos lo siguiente:

Pues ya de sus agudos y sutiles ingenios [de los mestizos], hábiles para todo género de letras, valga el voto del doctor Juan de Cuéllar, canónigo de la Santa Iglesia Catedral de la imperial Cozco, que, siendo maestro de los de mi edad y suerte, solía con tiernas lágrimas decirnos: "¡Oh hijos, y cómo quisiera ver una dozena de vosotros en la Universidad de Salamanca!', pareciéndole podían florecer las nuevas plantas del Perú en aquel jardín y vergel de sabiduría. Y por cierto que tierra tan fértil, de ricos minerales y metales preciosos, era razón criasse venas de sangre generosa y minas de entendimientos despiertos para todas artes y facultades, para las cuales no falta habilidad a los indios naturales y sobra capacidad a los mestizos, hijos de indias y españoles o de españolas e indios, y a los criollos, oriundos de acá, nascidos y connaturalizados allá ${ }^{12}$.

El discurso barroco de la nueva cultura tiene un agente virtual: el sujeto que trama la fertilidad de la naturaleza y la del intelecto; sujeto plural (indio, mestizo y criollo), hace del discurso, por lo pronto, su espacio multiétnico. Otra vez, la cultura adquiere la forma de una demanda política por los derechos del saber y la universalidad del conocer.

En este mismo Prólogo el Inca Garcilaso convoca a los "varones apostólicos"' (testigos de privilegio) para afirmar que "con las

${ }^{11}$ Sobre este punto puede verse mi ensayo "Para una teoría del texto latinoamericano: Colón, Garcilaso y el discurso de la abundancia", $R C L L, 1988$, núm. 28, pp. 101-115, donde se discute la construcción de este modelo. En cuanto a la representación y la descripción, puede consultarse MicHAEL BAXandall, Patterns of Intention, on the Historial Explanation of Pictures, Yale University Press, New Haven, 1985, así como MARGaret R. Miles, Visual Understanding in Western Christianity and Secular Culture, Beacon Press, Boston, 1985. Es muy útil el resumen crítico de DAVID CAST, "Humanism and Art", en el tomo de Albert Rabil ya citado (pp. 412-449). Todavía nos falta un estudio sistemático sobre la perspectiva, la percepción y el discurso cultural en América Latina.

12 Inca Garcilaso de la Vega, Historia general del Perú, Segunda parte de los Comentarios reales de los Incas, 3 ts., ed. de Angel Rosenblat, Emecé, Buenos Aires, 1944. 
primicias del espíritu" los indios "hacen a los de Europa casi la ventaxa que los de la iglesia primitiva a los cristianos de nuestra era'. La idea no es nueva, pero le sirve para reordenar la cronología, y hacer que la fe católica se desplace de Europa a Indias ("a residir con las antípodas"). Ello implica que los incas fueron cristianos sin saberlo, y que esperaban la evangelización para ser mejores cristianos que los europeos. Por lo mismo, su civilización moral podía competir con ventaja con Persia, Egipto, Grecia y Roma (Prólogo, pp. 9-10). Si ello ocurre en la dimensión religiosa y moral, en la política no es menor la calidad filosófica, la tolerancia y la sabiduría de su gobierno y su república, verdaderos modelos contrastantes de la violencia y la arbitrariedad de los poderes metropolitanos. En el capítulo 10 del libro sexto se lee: "Esta nación tan poderosa y tan amiga de perros, conquistó el Inca Cápac Yupanqui con regalos y halagos más que no con fuerza de arma porque pretendían ser señores de los ánimos antes que de los cuerpos". La noción colonial de conquista es aquí ajena a la práctica política imperial, y probablemente su uso es sólo contrastivo, ligeramente paradójico, ya que tampoco se trata de una "conquista espiritual" (lugar común difundido sin mayor escrutinio, que vale la pena poner en cuestión), sino de una distinta: la asociación política, pacífica y negociada ${ }^{13}$.

No obstante, a pesar de las evidencias y las promesas, la experiencia colonial está hecha también por la carencia. Y es sobre ella que la abundancia trabaja, no para ocultarla o diferirla, sino para denunciar, hasta donde es posible hacerlo, la disparidad entre la palabra y el hecho, entre el discurso ideológico y la práctica colonial. Después de todo, son las injusticias y agonías de la carencia las que agudizan las demandas de la abundancia posible. No es que una sea más real que la otra, sino que las pruebas de la abundancia deducen una virtualidad correctiva, una resolución política. Por eso, se lamenta el Inca: "Y con ser la tierra tan rica y abundante de oro y plata y piedras preciosas, como todo el mundo sabe, los naturales della son gente más pobre y mísera que hay en el universo" (cap. 4, libro octavo).

Esa conciencia trágica de la escritura es también una operación cultural reparadora. Luego del procesamiento, después del intercambio, la información, en efecto, debe ser preservada; y,

${ }^{13}$ Sobre este importante aspecto político puede verse el consistente análisis que hace Frances G. Crowley en su Garcilaso de la Vega, el Inca and his Sources in "Comentarios reales de los Incas", Mouton, The Hague, 1970. 
justamente, los Comentarios reales se definen por su sistema de conservación, que en la memoria, en el registro, en el testimonio, en la verificación y en la crítica organizan, al modo de un instrumento de auto-preservación, la información que debe ser salvada de la destrucción y proyectada, como ejemplo didáctico y como modelo virtual, al lector futuro, al Perú por hacerse. Lo dice el Inca: "Yo, incitado del deseo de la conservación de las antiguallas de mi patria, esas pocas que han quedado, porque no se pierdan del todo, me dispuse al trabajo tan excesivo como hasta aquí me ha sido y delante me ha de ser, el escribir su antigua república hasta acabarla"' (cap. 8, libro séptimo). Escribir es conversar: el libro equivale a la memoria pero también a la actualidad reparadora; y en él, como en un mapa del presente hecho por el pasado para que sea rehecho en el futuro, puede leerse a sí mismo ese Perú virtual, cuyas carencias deben ser reescritas por su abundancia.

La violencia, ciertamente, no deja de asombrar al Inca, por su gratuidad y ceguera. Hablando de una fortaleza derribada por los conquistadores, dice: "Desta manera echaron por tierra aquella gran majestad, indigna de tal estrago que eternamente hará lástima a los que la mirasen con atención de lo que fue; derribándola con tanta priesa que aun yo no alcancé della sino las pocas reliquias que he dicho'. $\mathrm{Y}$, sin embargo, los monumentos y virtudes del Incario están de pie en el libro, que los levanta y revela como la demostración del ingenio y la destreza de su pueblo, que ninguna conquista podría borrar.

Todo comienza ("a la puerta de este gran laberinto") en el interior del sujeto que se remonta a su infancia, a la lengua materna y al linaje indígena, " "para contar lo que en mis niñeces oí muchas vezes a mi madre y a sus hermanos y tíos y a otros sus mayores acerca deste origen y principio". El comienzo, en efecto, es la historia interna del sujeto que escribe la escena original de la voz, allí donde escucha y transcribe: "Y será mejor que se sepa por las propias palabras que los Incas lo cuentan que no por las de otros autores españoles". El autor es también un inca, y en el seno del habla materna recibe su propia voz. El sujeto habla de su propia historia cultural al trazar el origen de su relato histórico: el objeto narrado es el sujeto dialógico, construido por el cuento y el diálogo, por la memoria que le cede el encargo del habla de la tribu. El cuento es la información sobreviviente, que el narrador preserva. Ese testimonio mide lo perdido en la historia y lo recobrado en el discurso. Leemos: 
Es assí que, residiendo mi madre en el Cozco, su patria, venían a visitarla casi cada semana los pocos parientes y parientas que de las crueldades y tiranías de Atahuallpa [.. . ] escaparon, en las cuales visitas siempre sus más ordinarias pláticas eran tratar del origen de sus Reyes, de la majestad dellos, de la grandeza de su Imperio, de sus conquistas y hazañas, del gobierno que en paz y guerra tenían, de las leyes que tan en provecho y favor de sus vasallos ordenaban (cap. 15, libro primero).

Lo que sigue prefigura la historia del autor en el ritual del diálogo:

En estas pláticas yo, como muchacho, entraba y salía muchas veces donde ellos estavan, y me holgara de las oír, como huelgan los tales de oír fábulas. Passando pues días, meses y años, siendo ya yo de diez y seis o diez y siete años, acaesció que, estando mis parientes un día en esta su conversación hablando de sus Reyes y antiguallas, al más anciano dellos, que era el que dava cuenta dellas, le dixe: "-Inca, tío, pues no hay escritura entre vosotros, que es la que guarda la memoria de las cosas passadas ¿qué noticia tenéis del origen y principio de nuestros Reyes? Porque allá los españoles y las otras naciones, sus comarcanas, como tienen historias divinas y humanas, saben por ellas cuándo empezaron a reinar sus Reyes y los ajenos [...] que todo esto y mucho más saben por sus libros. Empero vosotros, que carecéis dellos ¿qué memoria tenéis de vuestras antiguallas?, ¿quién fue el primero de nuestros Incas?, ¿cómo se llamó?, ¿qué origen tuvo su linaje? [...] ¿qué origen tuvieron nuestras hazañas?"

[Y el tío le responde] "-Sobrino, yo te las diré de muy buena gana; a ti te conviene oírlas y guardarlas en el corazón (es frasis dellos por dezir en la memoria)".

Esta actualización de la escena primaria del diálogo está construida por una autodefinición del sujeto. El sujeto se excluye de su linaje, cuando dice "no hay escritura entre vosotros" pero se incluye en él cuando pregunta por el principio de "nuestros Reyes". Asimismo, se separa de los españoles cuando habla de "sus Reyes" y "sus libros". Y vuelve a distanciarse de los suyos cuando pregunta "vosotros ... ¿qué memoria tenéis de vuestras antiguallas?" Y, por fin, suma las personas del sujeto colectivo en "nuestros Incas” y “"nuestras hazañas"'. Esa oscilación de la pertenencia al grupo ocurre como una verdadera identificación del lugar pronominal desde donde habla del sujeto: habla desde el lenguaje que interroga al pasado, y pregunta por sí mismo al indagar por la 
historia colectiva. Pero si no pertenece al pasado (que es vuestro, de los ancianos) ni a los españoles (ellos se nombran en su propia historia, en sus libros), ¿desde dónde pregunta este sujeto? Pregunta desde el diálogo, desde ese umbral del futuro, donde no hay escritura incaica y donde la memoria oral y quechua, que él debe traducir, lo convierte en el heredero y en la herencia, en sujeto y objeto, al mismo tiempo, del pasado que se incribe en el presente como una profecía nativa. Por eso, la pregunta por la memoria del vosotros es respondida apelando a $t u$ memoria: tú eres quien debe recordar, responde el inca tío, anticipando la historia preservada en el Libro.

Y concluye el Inca:

Esta larga relación del origen de sus Reyes me dio aquel Inca, tío de mi madre, a quien yo se la pedí, la cual yo he procurado traducir fielmente de mi lengua materna, que es la del Inca, en la ajena, que es la castellana, aunque no la he escrito con la majestad de palabras que el Inca habló m con toda la significación que las de aquel lenguaje tiene, que, por ser tan significativo, pudiese haverse entendido mucho más de lo que se ha hecho.

No en vano el inca tío es llamado "tan buen archivo".

En la dedicatoria de los Diálogos de amor Garcilaso había escrito: "mi madre, la Palla doña Isabel, fue hija del Inca Gualpa Topac, uno de los hijos de Topac Inca Yupanqui y de la Palla Mama Ocllo, su legítima mujer, padre de Guayna Capac Inca, último rey que fue del Pirú" (p. 7). Garcilaso, entonces llamado Gómez Suárez de Figueroa, vivió con su madre y su padre, el noble y rico capitán español Garcilaso de la Vega, los doce primeros años de su vida, y la casa de Cusipata era frecuentada por la familia materna. La Palla Isabel Chimpu Ocllo, llamada Isabel Juárez, era nieta de Túpac Yupanqui, antepenúltimo emperador inca; y el inca tío, siendo "tío de mi madre", debe ser hermano de Gualpa Topac, esto es, otro de los hijos de Túpac Yupanqui. De tal manera que el inca tío es, en verdad, tío abuelo del Inca Garcilaso. Tratándose de Garcilaso, que se había demostrado prolijo en asuntos de su nobilísima genealogía española, estas precisiones no resultan vanas. Y, lo que es más importante, acontecen dentro del peculiar sistema de parentesco incaico, cuya trama intrincada podría iluminar el lugar desde donde el Inca Garcilaso habla ${ }^{14}$. Esa interioridad del linaje en la historia, del

14 Véase el trabajo de Floyd G. Lounsbury, "Some Aspects of the Inka 
sujeto cultural en el sujeto histórico, parece sugerir aquí que entre el bisabuelo (Túpac Yupanqui, el antepenúltimo emperador) y el bisnieto (el Inca Garcilaso), la cuarta instancia de la descendencia, se restablece el ciclo del linaje: el bisnieto se convierte en el reemplazo del bisabuelo, y otro ciclo empieza con él. El inca tío sería, así, el oficiante del ritual del parentesco, al trasladar en el joven mestizo el encargo de una nueva historia, de una memoria que recomienza. El diálogo es, por lo tanto, la escena emblemática de la autorrevelación: el joven, en la traslación escrita de la palabra oral, se transforma en el autor; escribir es su tarea, hacer el mapa de la memoria, el modelo de la patria realizada. Sólo que en lugar del linaje nos deja otro libro, hecho desde el quechua distintivo y desde el parentesco simbólico. Por eso, en la escritura, ha dejado de ser Gómez Suárez de Figueroa y se ha dado el nombre de Inca Garcilaso de la Vega, el primer inca de nombre español, sin reino y sin destino social, que debe construirse como sujeto en el libro de la memoria y del porvenir, de la historia y de la nueva cultura. Ese nombre, por lo demás, renombra a su padre y lo incorpora en la interioridad del nuevo sujeto a la familia de su madre. Simbólicamente, indianiza a España. Nombrando a una imagen del yo en el lenguaje de la nueva cultura, el escritor se inscribe en su propio libro como el primer habitante del discurso americano.

JuL1O OrTEGA Brown University

Kinship System", en John V. Murra et al. (eds.), Anthropological History of Andean Politics, Cambridge University Press, Cambridge, 1986, pp. 121-136; originalmente publicado como un número de Annales, Paris, 1978, vol. 33, núms. $5-6$. 
